\title{
Screening of dysphagia in relapsing-remitting multiple sclerosis patients in Montenegro
}

Jevto Lj. Eraković, MD, Ljiljana B. Radulović, MD, Zilha A. Idrizović, MD, Milovan B. Roganović, MD.

\section{ABSTRACT}

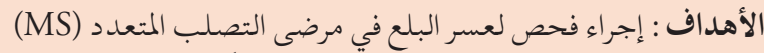

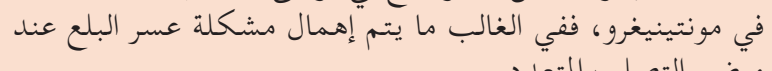
مرضى التصلب المتعلدد.

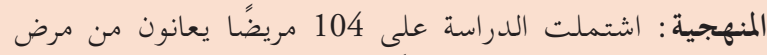

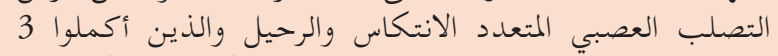

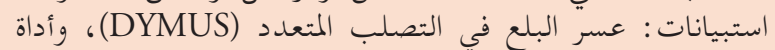

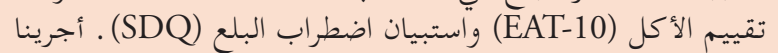

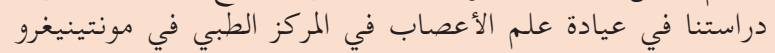

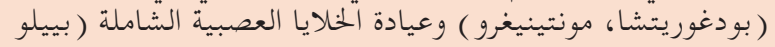

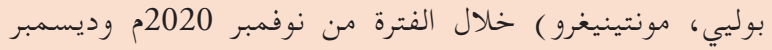
2020

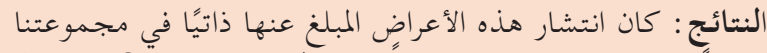

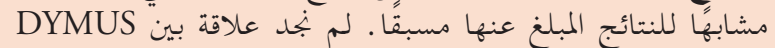

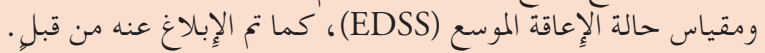

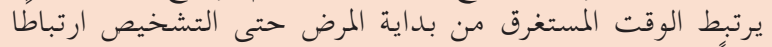

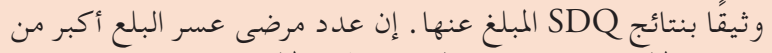

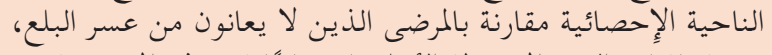

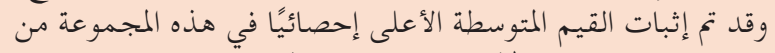

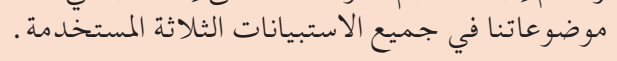

الحخلاصة: لا تكمن أهمية هذه المسألة في كونها تحذب من من سوء

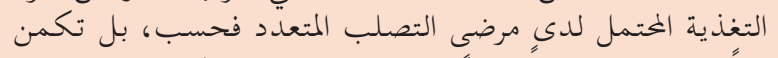

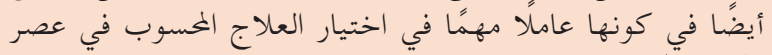
الأدوية ألمعدلة للمناعة عن طريقً مهنً في الفم.

Objectives: To perform screening of dysphagia in Montenegrin multiple sclerosis (MS) patients. Dysphagia is often neglected problem in patients with MS.

Methods: We included 104 patients with relapsingremitting MS who completed 3 questionnaires: dysphagia in multiple sclerosis (DYMUS), eating assessment tool-10 (EAT-10) and swallowing disturbance questionnaire (SDQ). Our study was performed in the clinic for neurology of the Clinical
Center of Montenegro (Podgorica, Montenegro) and Polyclinic Neuron (Bijelo Polje, Montenegro) between November 2020 and December 2020.

Results: Self-reported prevalence of this symptom in our group was simmilar to previously reported results. We did not find correlation between DYMUS and expanded disability status scale (EDSS), as it was reported before. Time spent from disease onset to diagnosis is strongly correlated with reported SDQ results. The population of dysphagia-patients is statistically significantly older compared to the non-dysphagia patients, and statistically higher mean values in this population of our subjects were proven on all 3 questionnaires used.

Conclusion: The importance of this issue is not just because it warns of potientially malnutrion in MS patients, but also important factor in therapy choosing algorithm in the era of orally used immunomodulatory drugs.

Neurosciences 2021; Vol. 26 (4): 331-338 doi: 10.17712/nsj.2021.4.20210063

From the Department of Neurology (Eraković, Radulović, Roganović), Clinical Centre of Montenegro, from the Faculty of Medicine (Radulovic, Roganović), University of Montenegro, Podgorica, and from the Polyclinic Neuron (Idrizović), Bijelo Polje, Montenegro.

Received 11th May 2021. Accepted 11th July 2021.

Address correspondence and reprint request to: Dr. Jevto Lj. Eraković, Clinic for Neurology, Clinical Centre of Montenegro, Podgorica, Montenegro.E-mail: jevto.erakovic@kccg.me

ORCID ID: https://orcid.org/0000-0002-2108-0746

M ultiple sclerosis (MS) is as a chronic neurological disease that can affect the swallowing process owing to demyelination of the myelin sheath. ${ }^{1}$ Dysphagia in MS occurs as a combination of damages in several structures, such as the corticobulbar nerve tract, cerebellum, brainstem, and lower cranial nerves. ${ }^{2}$ Mild swallowing problems are frequently overlooked by 
both physicians and patients among a broad array of neurological symptoms of MS. However, considering the possible complications of dysphagia (aspiration pneumonia, dehydration, malnutrition, and reduced quality of life), it is very important to pay close attention to this issue. ${ }^{3} \mathrm{~A}$ great number of researchers are working on screening tools for early diagnosis and identification of MS patients who are at risk of dysphagia, because earlier detection has the potential to lower costs and improve outcomes. ${ }^{4}$ The creation of multidisciplinary teams (ENT specialists, gastroenterologists, and neurologists) for treatment and monitoring of dysphagia leads to earlier identification of this problem in MS patients. The significance of dysphagia for patients with MS is even greater today, when an increasing number of orally used immunomodulatory drugs is appearing on the market.

According to one of the most recent meta-analyses on the prevalence of dysphagia in MS patients, the overall prevalence rate of dysphagia in MS patients was $43.33 \% .^{5}$ According to a Brazilian research, the progressive forms of MS (primary progressive and secondary progressive) were more frequently linked to severe dysphagia, whereas the relapsing-remitting form (RRMS) was linked to mild and moderate dysphagia. ${ }^{6}$ The disability level of expanded disability status scale (EDSS) and the length of the disease were revealed to be important predictors of dysphagia in MS patients by an Iranian group of investigators. ${ }^{7}$

Despite the availability of a swallowing rehabilitation program that can improve the swallowing function of MS patients with dysphagia, in cases of increasing dysphagia, a gastrostomy tube may be the only option for optimal feeding. ${ }^{8}$ According to a newly published finding, the median period from MS diagnosis to gastrostomy was 17.8 years, and the median survival duration following gastrostomy was 21.73 months (based on a sample size of 53 MS patients). ${ }^{9}$

It is believed that there are roughly $650 \mathrm{MS}$ patients in Montenegro, a country with a population of approximately 650,000 people, with approximately 400 of them having RRMS.

The aim of our study was to perform screening of dysphagia in RRMS patients in Montenegro, as well as to correlate characteristics of dysphagia with demographic and clinical features of study group.

Disclosure. Authors have no conflict of interests, and the work was not supported or funded by any drug company.
Methods. Our cross-sectional study included 104 patients with RRMS who underwent an examination in the clinic for neurology of the Clinical Center of Montenegro (Podgorica, Montenegro) and Polyclinic Neuron (Bijelo Polje, Montenegro) from November 2020 to December 2020. Approval was obtained from the ethics committee of the Clinical Centre of Montenegro (No: 03/01-23457/1). The procedures used in this study were according to the principles of Helsinki Declaration. Inclusion criteria for participation in our study were diagnosis of RRMS and age $\geq 18$. Exclusion criteria were diagnosis of primary progressive multiple sclerosis (PPMS), secondary progressive multiple sclerosis (SPMS) and other neurological diseases as well as age $<18$. After getting acquainted with the goals of the research and the methodology, all patients signed an informed consent form before joining the research.

Questionnaires. We applied the dysphagia in multiple sclerosis (DYMUS), eating assessment tool-10 (EAT-10), and swallowing disturbance questionnaire (SDQ) questionnaires to conduct our study. The presence or absence of relevant symptoms was determined using the DYMUS questionnaire, which consisted of 10 yes/no questions. ${ }^{10}$ A score $\geq 3$ was considered abnormal. Patients were asked to reply to all of the statements in the EAT-10 questionnaire and to rate the severity of their difficulties on a scale of $0-4$ (where 0 indicated no problems and 4 indicated severe problems). ${ }^{11}$ An EAT-10 score $\geq 3$ was considered to be indicative of possible dysphagia. The SDQ consisted of 15 questions. The first 14 questions were scored on a grade scale of $0-3$ (where 0 indicated no disorders and 3 indicated severe disorders), and the last question was a yes/no question (scored 0.5 points if the response was "no" and 2.5 points if the response was "yes"). An overall score $\geq 12.5$ points was considered abnormal. ${ }^{12}$

Statistical analysis. Data was analyzed using the Statistical Package for Social Sciences (SPSS) software version 23.0 (IBM Corp., Armonk, NY, USA). We used the chi-square test for homogeneity in order to evaluate whether there was a statistically significant difference in the distributions of different populations of respondents. We used a 5\% significance level, namely, we will reject the hypothesis that the populations are homogenous if the $p$-value is $<0.05$. Additionally, we calculated the Pearson's correlation coefficients and used linear regression to examine whether there was a statistically significant correlation between various parameters evaluated in the research.

Results. After excluding 2 patients from the study owing to an incomplete questionnaire, our sample included 102 patients. Of these 102 patients, 24 
(23.5\%) were male patients and $78(76.5 \%)$ were female patients, and the mean age was $38.2 \pm 9.7$ years. The mean duration of illness in our subjects was $6.3 \pm 5.5$

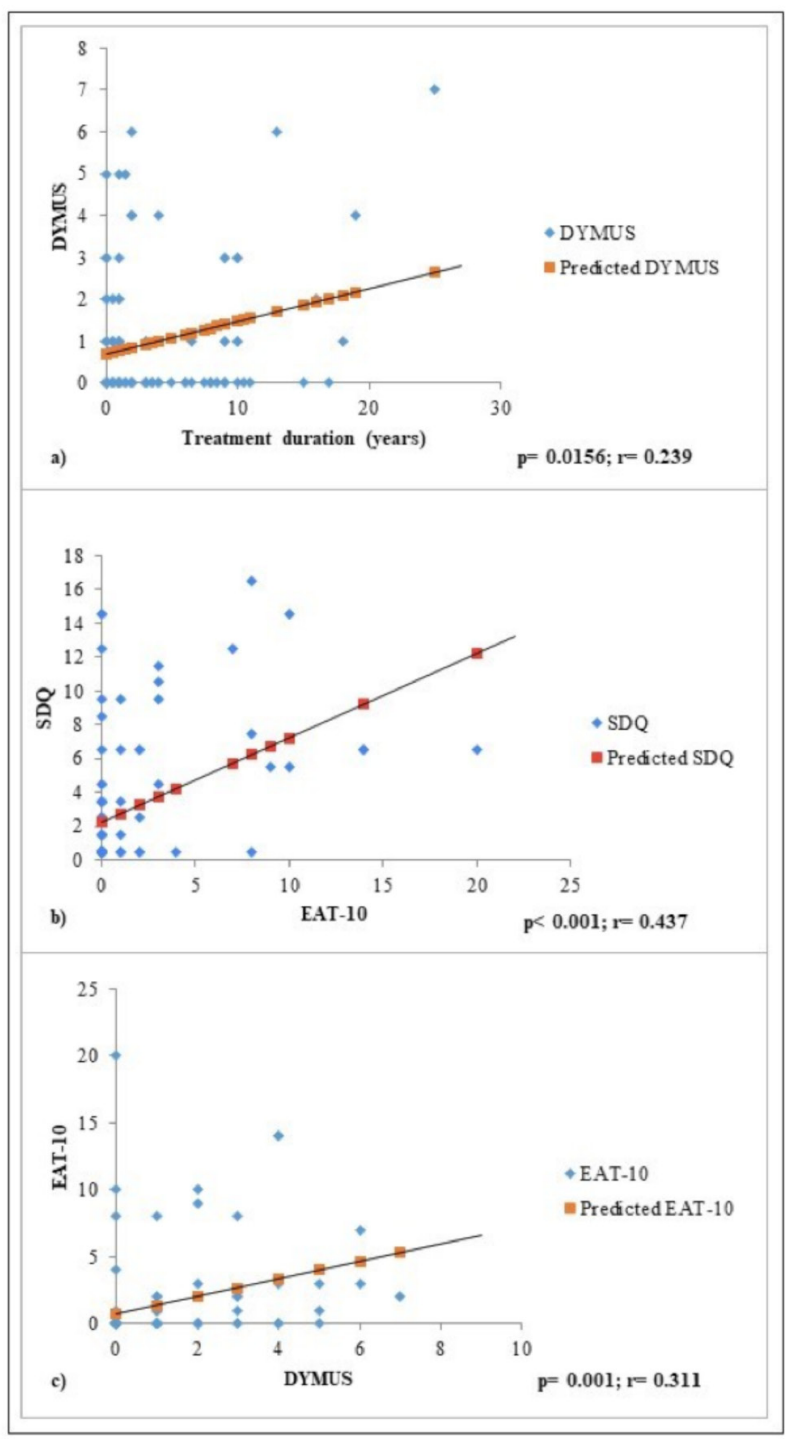

Figure 1 - Statistically relevant correlations. years, the mean time to diagnosis was $2.5 \pm 3.8$ years, and the mean period from diagnosis to the start of diseasemodifying therapy (DMT) was $2.5 \pm 3.3$ years. At the time of examination, the mean EDSS score was 2.9 \pm 1.2. Regarding the number of relapses, the largest number of respondents had one (32 respondents, 31.4\%) and 2 (25 respondents, $24.5 \%$ ) relapses in the course of the disease, $14(13.7 \%)$ respondents had 3 relapses, $15(14.7 \%)$ had 4 relapses by the time of the study, and $16(15.7 \%)$ had 5 or more relapses. Concerning the DM that patients used, most patients (72 patients, $70.6 \%)$ were on first-line drugs, and $8(7.8 \%)$ patients were in one of the following 3 groups: patients switched to second-line drugs after first-line drugs; patients on second-line drugs as a first therapy choice, and patients not using DMT. We had one (1.0\%) patient using only third-line therapy and 5 (4.9\%) patients using third-line drugs after using first- and second-line drugs. The mean duration of therapy was $3.8 \pm 5.0$ years.

Table 1 shows the prevalence of dysphagia in our subjects in relation to each questionnaire used. A detailed overview of the answers to all questions from the 3 questionnaires is provided in Tables $2,3 \& 4$.

Table 5 shows the clinical and demographic characteristics of our patients in relation to the 3 questionnaires used in our study. In terms of statistical correlations, we found 3 significant correlations, as shown in Figure 1.

In order to compare demographic and clinical characteristics in our subjects, they were divided into the following 2 groups: dysphagia patients (abnormal results in at least one of the applied questionnaires) and non-dysphagia patients (normal results in all 3 applied questionnaires). The obtained results are shown in Table 6.

Discussion. The group of respondents included in our study made up approximately $25 \%$ of the total number of RRMS patients in Montenegro, and their gender distribution corresponded to the recent knowledge of MS gender distribution (female-to-male ratio of 2.3-3.5:1). ${ }^{13}$

Table 1 - The prevalence of dysphagia in study subjects according to questionnaire ( $\mathrm{n}=102)$.

\begin{tabular}{|c|c|c|c|c|}
\hline Questionnaire & Cut-off score & Maximum achievable score & Mean score (min-max) & $\begin{array}{c}\text { Prevalence of dysphagia } \\
\text { n (\%) }\end{array}$ \\
\hline EAT-10 & $\geq 3$ points & 40 points & $1.38(0-20)$ & $15(14.71)$ \\
\hline DYMUS & $\begin{array}{c}\geq 1 \text { points } \\
\geq 3 \text { points (severe dysphagia) }\end{array}$ & 10 points & $0.99(0-7)$ & $\begin{array}{l}40(39.21) \\
17(16.67)\end{array}$ \\
\hline SDQ & $\geq 12.5$ points & 44.5 points & $2.94(0.5-16.5)$ & $6(5.88)$ \\
\hline
\end{tabular}


Table 2 - A detailed overview of responses of patients to DYMUS questionnaire.

\begin{tabular}{|c|c|c|}
\hline \multirow[t]{2}{*}{ DYMUS Questionnaire } & Yes & No \\
\hline & \multicolumn{2}{|c|}{ n (\%) } \\
\hline $\begin{array}{l}\text { Do you have difficulties swallowing solid food (such as } \\
\text { meat, bread and the like)? }\end{array}$ & $10(9.80)$ & $92(90.20)$ \\
\hline $\begin{array}{l}\text { Do you have difficulties swallowing liquids (such as water, } \\
\text { milk, and the like)? }\end{array}$ & $4(3.92)$ & $98(96.08)$ \\
\hline $\begin{array}{l}\text { Do you have a globus sensation in your throat during } \\
\text { swallowing? }\end{array}$ & $7(6.86)$ & $95(93.14)$ \\
\hline Do you have food sticking in your throat? & $11(10.78)$ & $91(89.22)$ \\
\hline $\begin{array}{l}\text { Do you cough or do you have a chocking sensation after } \\
\text { ingesting solid foods? }\end{array}$ & $8(7.84)$ & $94(92.16)$ \\
\hline $\begin{array}{l}\text { Do you cough or do you have a chocking sensation after } \\
\text { ingesting liquids? }\end{array}$ & $5(4.90)$ & $97(95.10)$ \\
\hline $\begin{array}{l}\text { Do you need to swallow several times before completely } \\
\text { swallowing solid food? }\end{array}$ & $16(15.69)$ & $86(84.31)$ \\
\hline $\begin{array}{l}\text { Do you need to cut food in small pieces before } \\
\text { swallowing? }\end{array}$ & $13(12.75)$ & $89(87.25)$ \\
\hline $\begin{array}{l}\text { Do you need to take many sips before completely } \\
\text { swallowing liquid? }\end{array}$ & $9(8.82)$ & $93(91.18)$ \\
\hline Do you have weight loss? & $18(17.65)$ & $84(82.35)$ \\
\hline
\end{tabular}

Table 3 - A detailed overview of responses of patients to EAT-10 questionnaire.

\begin{tabular}{|c|c|c|c|c|c|}
\hline EAT-10 questionnaire & 0 & 1 & $\begin{array}{c}2 \\
\mathrm{n}(\%)\end{array}$ & 3 & 4 \\
\hline $\begin{array}{l}\text { My swallowing problem has caused } \\
\text { me to lose weight. }\end{array}$ & $92(90.20)$ & $8(7.84)$ & $1(0.98)$ & $0(0.00)$ & $1(0.98)$ \\
\hline $\begin{array}{l}\text { My swallowing problem interferes } \\
\text { with my ability to go out for meals. }\end{array}$ & $95(93.14)$ & $4(3.92)$ & $3(2.94)$ & $0(0.00)$ & $0(0.00)$ \\
\hline Swallowing liquids takes extra effort. & $93(91.18)$ & $5(4.90)$ & $4(3.92)$ & $0(0.00)$ & $0(0.00)$ \\
\hline Swallowing solids takes extra effort. & $87(85.29)$ & $9(8.82)$ & $6(5.88)$ & $0(0.00)$ & $0(0.00)$ \\
\hline Swallowing pills takes extra effort. & $90(88.24)$ & $4(3.92)$ & $8(7.84)$ & $0(0.00)$ & $0(0.00)$ \\
\hline Swallowing is painful. & $99(97.06)$ & $1(0.98)$ & $2(1.96)$ & $0(0.00)$ & $0(0.00)$ \\
\hline $\begin{array}{l}\text { The pleasure of eating is affected by } \\
\text { my swallowing. }\end{array}$ & $92(90.20)$ & $5(4.90)$ & $4(3.92)$ & $0(0.00)$ & $1(0.98)$ \\
\hline $\begin{array}{l}\text { When I swallow food sticks in my } \\
\text { throat. }\end{array}$ & $91(89.22)$ & $4(3.92)$ & $5(4.90)$ & $0(0.00)$ & $2(1.96)$ \\
\hline I cough when I eat. & $96(94.12)$ & $4(3.92)$ & $2(1.96)$ & $0(0.00)$ & $0(0.00)$ \\
\hline Swallowing is stressful. & $95(93.14)$ & $3(2.94)$ & $4(3.92)$ & $0(0.00)$ & $0(0.00)$ \\
\hline
\end{tabular}

The prevalence of dysphagia according to the questionnaires used in our research was similar to that reported in a recent published paper by Milewska et al. ${ }^{14}$ It was surprising that almost $40 \%$ of patients with RRMS in Montenegro reported dysphagia in the DYMUS questionnaire as a symptom of the disease. However, this is confirmed by previous research emphasizing that dysphagia is a present but often neglected problem in MS patients. It is important to emphasize that DYMUS is the preferred method of dysphagia screening in clinical practice. ${ }^{15}$ According to the DYMUS questionnaire, $16.67 \%$ of our respondents had dysphagia, indicating that every 7 th respondent was a MS patient with severe dysphagia. This result is especially important when considering the fact that the DYMUS questionnaire can be a useful clinical tool for red flagging patients who should undergo objective testing and should be referred to a otorhinolaryngologist. ${ }^{16}$

Looking more closely, 18 (17.65\%) patients reported weight loss as a symptom, as part of the 
Table 4 - A detailed overview of responses of patients to SDQ questionnaire.

\begin{tabular}{|c|c|c|c|c|}
\hline SDQ & Never & $\begin{array}{r}\text { Once a month or less } \\
\mathbf{n}\end{array}$ & $\begin{array}{l}\text { 1-7 times a week } \\
\%)\end{array}$ & $>7$ times a week \\
\hline $\begin{array}{l}\text { Do you experience difficulty chewing solid food, } \\
\text { like an apple, cookie or a cracker? }\end{array}$ & $86(84.31)$ & $13(12.75)$ & $1(0.98)$ & $1(0.98)$ \\
\hline $\begin{array}{l}\text { Are there any food residues in your mouth, } \\
\text { cheeks, under your tongue or stuck to your nose } \\
\text { when you eat or drink? }\end{array}$ & $78(76.47)$ & $20(19.61)$ & $1(0.98)$ & $2(1.96)$ \\
\hline $\begin{array}{l}\text { Does food or liquid come out of your nose when } \\
\text { you eat or drink? }\end{array}$ & $91(89.22)$ & $10(9.80)$ & $0(0.00)$ & $0(0.00)$ \\
\hline Does chewed up food dribble from your mouth? & $93(91.18)$ & $7(6.86)$ & $1(0.98)$ & $0(0.00)$ \\
\hline $\begin{array}{l}\text { Do you feel you have too much saliva in } \\
\text { your mouth; do you drool or have difficulty } \\
\text { swallowing your saliva? }\end{array}$ & $86(84.31)$ & $14(13.73)$ & $1(0.98)$ & $1(0.98)$ \\
\hline $\begin{array}{l}\text { Do you swallow chewed up food several times } \\
\text { before it goes down your throat? }\end{array}$ & $87(85.29)$ & $13(12.75)$ & $1(0.98)$ & $0(0.00)$ \\
\hline $\begin{array}{l}\text { Do you experience difficulty in swallowing solid } \\
\text { food (i.e. do apples or crackers get stuck in your } \\
\text { throat)? }\end{array}$ & $84(82.35)$ & $16(15.69)$ & $0(0.00)$ & $1(0.98)$ \\
\hline $\begin{array}{l}\text { Do you experience difficulty in swallowing } \\
\text { pureed food? }\end{array}$ & $93(91.18)$ & $8(7.84)$ & $0(0.00)$ & $0(0.00)$ \\
\hline $\begin{array}{l}\text { While eating, do you feel as if a lump of food is } \\
\text { stuck in your throat? }\end{array}$ & $87(85.29)$ & $13(12.75)$ & $0(0.00)$ & $1(0.98)$ \\
\hline Do you cough while swallowing liquids? & $92(90.20)$ & $7(6.86)$ & $1(0.98)$ & $1(0.98)$ \\
\hline Do you cough while swallowing solid food? & $92(90.20)$ & $9(8.82)$ & $0(0.00)$ & $1(0.98)$ \\
\hline $\begin{array}{l}\text { Immediately after eating or drinking, do you } \\
\text { experience a change in your voice, such as } \\
\text { hoarseness or reduced? }\end{array}$ & $87(85.29)$ & $14(13.73)$ & $0(0.00)$ & $1(0.98)$ \\
\hline $\begin{array}{l}\text { Other than during meals, do you experience } \\
\text { coughing or difficulty breathing as a result of } \\
\text { saliva entering your windpipe? }\end{array}$ & $81(79.41)$ & $18(17.65)$ & $1(0.98)$ & $1(0.98)$ \\
\hline $\begin{array}{l}\text { Do you experience difficulty in breathing during } \\
\text { meals? }\end{array}$ & $86(84.31)$ & $13(12.75)$ & $2(1.96)$ & $0(0.00)$ \\
\hline \multicolumn{5}{|c|}{ Have you suffered from a respiratory infection (pneumonia, bronchitis) during the past year? } \\
\hline $\begin{array}{l}\text { Yes } \\
\text { No }\end{array}$ & \multicolumn{4}{|c|}{$\begin{aligned} 7(6.86) \\
95(93.14)\end{aligned}$} \\
\hline
\end{tabular}

DYMUS questionnaire. In our opinion, this number is too large, and it might be a reflection of current stressful events related to COVID-19, because MS patients are, according to our study, concern about the future status of the disease in the current epidemic era. ${ }^{17}$ The large number of patients with weight loss might also be associated with the season in which the examination was performed (summer). Interestingly, almost an identical percentage of respondents answered in the affirmative to this question during the validation of the Portuguese DYMUS questionnaire. ${ }^{18}$

Certainly, the fact that every 10th respondent $(9.80 \%)$ stated that he/she has problems swallowing solid food should not be overlooked. According to the SDQ, the frequency of this problem in most respondents was once a month or less often. From the obtained results, we noted that once a month, 19.61\% of respondents experienced food residues in the mouth, in the cheeks, under the tongue, or stuck to the nose on eating or drinking. These data suggest the need to expand routine anamnestic issues to regular patient check-ups.

We did not find a correlation between the DYMUS questionnaire findings and EDSS, as was reported in other studies. ${ }^{10,19}$ Additionally, we did not find a correlation between the EAT-10 questionnaire findings and EDSS or between the SDQ findings and EDSS. Our study confirmed the previously reported strong correlation between the DYMUS and EAT-10 questionnaire findings and showed a strong correlation between the EAT-10 questionnaire and SDQ findings $(p<0.001, \mathrm{r}=0.437) .{ }^{20}$

Our results showed a correlation of the age of our respondents with the DYMUS questionnaire findings, 
Table 5 - Correlation between EAT-10, DYMUS and SDQ with demographic and clinical characteristics of respondents.

\begin{tabular}{|c|c|c|c|c|c|c|c|}
\hline \multirow[t]{2}{*}{ Characteristics } & \multirow[t]{2}{*}{$\mathrm{n}$} & \multicolumn{2}{|c|}{ EAT-10 } & \multicolumn{2}{|c|}{ DYMUS } & \multicolumn{2}{|c|}{ SDQ } \\
\hline & & Mean \pm SD & P-value & Mean \pm SD & $P$-value & Mean \pm SD & $P$-value \\
\hline \multicolumn{8}{|l|}{ Gender } \\
\hline $\begin{array}{l}\text { Male } \\
\text { Female }\end{array}$ & $\begin{array}{l}24 \\
78\end{array}$ & $\begin{array}{l}1.46 \pm 3.61 \\
1.36 \pm 3.42\end{array}$ & 0.756 & $\begin{array}{l}0.67 \pm 1.13 \\
1.09 \pm 1.76\end{array}$ & 0.456 & $\begin{array}{l}2.67 \pm 3.45 \\
3.03 \pm 4.06\end{array}$ & 0.683 \\
\hline \multicolumn{8}{|l|}{ Age (years) } \\
\hline $\begin{array}{l}18-24 \\
25-30 \\
31-37 \\
38-43 \\
44-49 \\
50-56 \\
56-62 \\
63-69\end{array}$ & $\begin{array}{c}8 \\
16 \\
28 \\
17 \\
22 \\
7 \\
1 \\
3\end{array}$ & $\begin{array}{c}2.63 \pm 7.03 \\
0.375 \pm 0.72 \\
1.29 \pm 2.83 \\
0.94 \pm 2.46 \\
1.86 \pm 4.30 \\
3.00 \pm 3.65 \\
0.00 \pm 0.00 \\
0.00 \pm 0.00\end{array}$ & 0.249 & $\begin{array}{l}0.12 \pm 0.35 \\
1.06 \pm 0.85 \\
0.50 \pm 1.23 \\
0.82 \pm 1.51 \\
1.32 \pm 1.64 \\
3.71 \pm 2.98 \\
0.00 \pm 0.00 \\
0.00 \pm 0.00\end{array}$ & 0.001 & $\begin{array}{l}1.25 \pm 2.12 \\
3.62 \pm 4.75 \\
1.93 \pm 2.96 \\
2.44 \pm 3.88 \\
3.86 \pm 4.33 \\
7.07 \pm 3.64 \\
0.50 \pm 0.00 \\
0.50 \pm 0.00\end{array}$ & 0.652 \\
\hline \multicolumn{8}{|c|}{ Number of relapses } \\
\hline $\begin{array}{l}1 \\
2 \\
3 \\
4 \\
5 \text { or more }\end{array}$ & $\begin{array}{l}31 \\
26 \\
14 \\
15 \\
16\end{array}$ & $\begin{array}{l}2.32 \pm 5.22 \\
0.65 \pm 1.77 \\
1.64 \pm 3.27 \\
0.87 \pm 1.19 \\
1.00 \pm 2.53\end{array}$ & 0.754 & $\begin{array}{l}0.78 \pm 1.39 \\
0.96 \pm 1.79 \\
0.93 \pm 1.73 \\
1.00 \pm 1.65 \\
1.50 \pm 1.86\end{array}$ & 0.768 & $\begin{array}{l}2.72 \pm 3.74 \\
2.46 \pm 3.70 \\
4.21 \pm 5.58 \\
2.57 \pm 3.63 \\
3.37 \pm 3.24\end{array}$ & 0.084 \\
\hline \multicolumn{8}{|c|}{ EDSS at examination time } \\
\hline $\begin{array}{l}1-2 \\
2.5-3.5 \\
4-5 \\
5.5-6.5\end{array}$ & $\begin{array}{c}39 \\
40 \\
19 \\
4\end{array}$ & $\begin{array}{l}1.69 \pm 3.66 \\
0.92 \pm 2.38 \\
1.74 \pm 4.99 \\
1.25 \pm 1.50\end{array}$ & 0.726 & $\begin{array}{l}0.87 \pm 1.32 \\
0.85 \pm 1.49 \\
1.26 \pm 2.16 \\
2.25 \pm 2.87\end{array}$ & 0.528 & $\begin{array}{l}2.55 \pm 3.51 \\
2.70 \pm 3.92 \\
3.92 \pm 4.53 \\
4.50 \pm 4.90\end{array}$ & 0.762 \\
\hline \multicolumn{8}{|c|}{ Time to diagnosis (years) } \\
\hline $\begin{array}{l}\text { Up to } 1 \\
1-2 \\
3-4 \\
5-6 \\
7-8 \\
9 \text { or more }\end{array}$ & $\begin{array}{l}37 \\
40 \\
5 \\
5 \\
6 \\
9\end{array}$ & $\begin{array}{l}2.00 \pm 4.79 \\
1.17 \pm 2.47 \\
0.00 \pm 0.00 \\
2.00 \pm 3.08 \\
0.00 \pm 0.00 \\
1.11 \pm 2.67\end{array}$ & 0.144 & $\begin{array}{l}1.00 \pm 1.60 \\
0.82 \pm 1.43 \\
0.20 \pm 0.45 \\
2.80 \pm 2.95 \\
0.00 \pm 0.00 \\
1.78 \pm 1.98\end{array}$ & 0.196 & $\begin{array}{l}2.18 \pm 2.91 \\
2.55 \pm 3.52 \\
1.50 \pm 0.71 \\
6.50 \pm 4.74 \\
6.17 \pm 6.53 \\
4.50 \pm 5.77\end{array}$ & 0.001 \\
\hline \multicolumn{8}{|c|}{ Disease duration (years) } \\
\hline $\begin{array}{l}0-2 \\
3-6 \\
7-9 \\
10-13 \\
14-18 \\
19 \text { or more }\end{array}$ & $\begin{array}{c}36 \\
20 \\
17 \\
20 \\
5 \\
4\end{array}$ & $\begin{array}{l}1.36 \pm 2.76 \\
2.65 \pm 5.90 \\
0.94 \pm 2.30 \\
0.20 \pm 0.52 \\
3.40 \pm 4.78 \\
0.50 \pm 1.00\end{array}$ & 0.534 & $\begin{array}{l}0.67 \pm 1.22 \\
1.35 \pm 1.90 \\
0.94 \pm 1.68 \\
0.70 \pm 1.08 \\
1.60 \pm 2.61 \\
3.00 \pm 3.16\end{array}$ & 0.935 & $\begin{array}{l}3.28 \pm 4.91 \\
2.70 \pm 3.07 \\
3.09 \pm 3.54 \\
1.55 \pm 1.73 \\
3.90 \pm 5.27 \\
6.25 \pm 4.50\end{array}$ & 0.119 \\
\hline \multicolumn{8}{|c|}{ Period from diagnosis to start of treatment (years) } \\
\hline $\begin{array}{l}0-1 \\
2-3 \\
4-5 \\
6-7 \\
8 \text { or more }\end{array}$ & $\begin{array}{c}63 \\
15 \\
9 \\
4 \\
11\end{array}$ & $\begin{array}{l}1.17 \pm 3.07 \\
1.33 \pm 2.61 \\
4.00 \pm 6.84 \\
0.25 \pm 0.50 \\
0.91 \pm 2.70\end{array}$ & 0.567 & $\begin{array}{l}0.81 \pm 1.52 \\
1.93 \pm 1.90 \\
1.78 \pm 2.49 \\
0.50 \pm 0.58 \\
0.45 \pm 0.69\end{array}$ & 0.294 & $\begin{array}{l}2.65 \pm 3.66 \\
3.71 \pm 4.85 \\
5.94 \pm 5.59 \\
1.50 \pm 2.00 \\
1.86 \pm 1.63\end{array}$ & 0.879 \\
\hline \multicolumn{8}{|c|}{ Treatment duration (years) } \\
\hline $\begin{array}{l}0-1 \\
2-3 \\
4-5 \\
6-7 \\
8-9 \\
10 \text { or more }\end{array}$ & $\begin{array}{c}48 \\
21 \\
6 \\
4 \\
9 \\
14\end{array}$ & $\begin{array}{l}1.65 \pm 3.91 \\
1.90 \pm 4.17 \\
0.00 \pm 0.00 \\
0.25 \pm 0.50 \\
0.22 \pm 0.67 \\
1.36 \pm 3.13\end{array}$ & 0.284 & $\begin{array}{l}0.81 \pm 1.27 \\
1.19 \pm 2.02 \\
0.67 \pm 1.63 \\
0.25 \pm 0.50 \\
0.50 \pm 1.07 \\
2.00 \pm 2.32\end{array}$ & 0.123 & $\begin{array}{l}3.04 \pm 4.35 \\
3.02 \pm 3.66 \\
2.00 \pm 3.67 \\
3.25 \pm 2.36 \\
1.62 \pm 2.10 \\
3.71 \pm 4.28\end{array}$ & 0.001 \\
\hline & & $\begin{array}{l}\text { eating assessm } \\
\text { questionna }\end{array}$ & $\begin{array}{r}\text {, DY } \\
-\operatorname{stan}\end{array}$ & $\begin{array}{l}\text { ysphagia in } n \\
\text { iation, EDSS }\end{array}$ & $\begin{array}{l}\text { sclerosi } \\
\text { ided D }\end{array}$ & $\begin{array}{l}\text { swallowing } \\
\text { tatus Scale }\end{array}$ & \\
\hline
\end{tabular}

but not with the findings of the other 2 questionnaires used. Elderly patients are expected to report symptoms of dysphagia to a greater extent. ${ }^{21}$ Additionally, in our results, time spent from disease onset to diagnosis of MS was strongly correlated with the SDQ findings. This confirms that early diagnosis of MS is a prerequisite for 
Table 6 - Comparision of demographic and clinical characteristics of dysphagia- and non-dysphagia patients.

\begin{tabular}{|c|c|c|c|c|}
\hline \multirow[t]{2}{*}{ Characteristic } & All patients $(\mathrm{N}=102)$ & Dysphagia patients* $(n=46)$ & Non-dysphagia patients $(\mathrm{n}=56)$ & $P$-value \\
\hline & \multicolumn{4}{|c|}{ Mean \pm SD } \\
\hline Gender distribution (M:F) & $24: 78$ & $9: 37$ & $15: 41$ & 0.392 \\
\hline Age & $38.18 \pm 9.77$ & $40.82 \pm 12.81$ & $37.1 \pm 9.02$ & $<0.001$ \\
\hline Number of relapses & $2.58 \pm 1.46$ & $2.84 \pm 1.55$ & $2.45 \pm 1.45$ & 0.414 \\
\hline Time to diagnosis (years) & $2.45 \pm 3.76$ & $2.63 \pm 4.27$ & $2.34 \pm 3.44$ & 0.448 \\
\hline EDSS & $2.91 \pm 1.22$ & $3.10 \pm 1.25$ & $2.84 \pm 1.23$ & 0.795 \\
\hline $\begin{array}{l}\text { Period from diagnosis to start of } \\
\text { treatment (years) }\end{array}$ & $2.54 \pm 3.55$ & $2.58 \pm 2.69$ & $2.55 \pm 3.95$ & 0.366 \\
\hline Disease duration (years) & $6.26 \pm 5.46$ & $6.33 \pm 5.95$ & $6.22 \pm 5.25$ & 0.235 \\
\hline Treatment duration (years) & $3.81 \pm 5.01$ & $3.91 \pm 5.92$ & $3.72 \pm 4.24$ & 0.292 \\
\hline DYMUS result & $0.99 \pm 1.94$ & $2.11 \pm 1.75$ & $0.11 \pm 0.79$ & $<0.001$ \\
\hline SDQ result & $2.94 \pm 3.91$ & $5.43 \pm 4.67$ & $0.89 \pm 0.85$ & 0.005 \\
\hline EAT-10 result & $1.38 \pm 3.44$ & $3.04 \pm 4.63$ & $0.02 \pm 0.13$ & $<0.001$ \\
\hline
\end{tabular}

achieving favorable therapeutic effects in MS patients. Treatment duration was correlated with the SDQ findings. It should be noted that a close correlation was present between treatment duration and the DYMUS questionnaire findings, as shown in Figure 1 ( $p=0.0156$, $\mathrm{r}=0.239$ ).

As mentioned earlier, Table 6 shows the demographic and clinical characteristics of patients who had an abnormal result on at least one of the questionnaires (labeled as dysphagia patients) and those who had a normal result on all 3 questionnaires (labeled as non-dysphagia patients). The population of dysphagia patients was significantly older compared with the population of non-dysphagia patients, and in this population, statistically higher mean values were obtained in all 3 questionnaires used. Our study did not identify a statistically significant difference in other clinical features, such as EDSS and mean disease duration, which is consistent with findings from previous studies. ${ }^{5}$

Limitations. Our study had a limitation in that it did not include individuals who were in remission or who did not have regular check-ups. Another limitation was that the questionnaires took approximately 20 minutes to complete, and fatigue may have had an impact on patient responses. Moreover, cognitive changes are present in patients with MS, and they might have had some influence on patient responses.

In conclusion, our results suggest that the prevalence of dysphagia in RRMS patients in Montenegro is high, and since it is often disregarded by both patients and physicians, it is necessary to pay additional attention to this problem. Any of the questionnaires used in our study can be incorporated in a routine follow-up as an initial assessment. Patients with scores indicating dysphagia may then be prompted to undergo further evaluation. The teamwork of neurologists, gastroenterologists, and otorhinolaryngologists would improve the process of diagnosing, treating, and monitoring dysphagia in RRMS patients in Montenegro. Further work foreseen includes an extensive study of dysphagia problems in a larger number of MS patients, as well as on other phenotypes of MS (progressive forms).

Acknowledgment. The authors gratefully acknowledge Wordvice (https://wordvice.com/) for English Language Editing.

\section{References}

1. Covello F, Ruoppolo G, Carissimo C, Zumbo G, Ferrara C, Polimeni A, et al. Multiple sclerosis: impact on oral hygiene, dysphagia, and quality of life. Int J Environ Res Public Health 2020; 17: 3979 .

2. Solaro C, Rezzani C, Trabucco E, Amato MP, Zipoli V, Portaccio E, et al. Prevalence of patient-reported dysphagia in multiple sclerosis patients: an Italian multicenter study (using the DYMUS questionnaire). J Neurol Sci 2013; 331: 94-97.

3. Wirth R, Dziewas R, Beck AM, Clavé P, Hamdy S, Heppner $\mathrm{HJ}$, et al. Oropharyngeal dysphagia in older persons - from pathophysiology to adequate intervention: a review and summary of an international expert meeting. Clin Interv Aging 2016; 11: 189-208.

4. Ansari NN, Tarameshlu M, Ghelichi L. Dysphagia in multiple sclerosis patients: diagnostic and evaluation strategies. Degener Neurol Neuromuscul Dis 2020; 10: 15-28.

5. Aghaz A, Alidad A, Hemmati E, Jadidi H, Ghelichi L. Prevalence of dysphagia in multiple sclerosis and its related factors: systematic review and meta-analysis. Iran J Neurol 2018; 17: 180-188. 
6. Fernandes AM, Duprat Ade C, Eckley CA, Silva Ld, Ferreira RB, Tilbery CP. Oropharyngeal dysphagia in patients with multiple sclerosis: do the disease classification scales reflect dysphagia severity? Braz J Otorhinolaryngol 2013; 79: 460-465.

7. Tarameshlu M, Azimi AR, Ghelichi L, Ansari NN. Prevalence and predictors of dysphagia in Iranian patients with multiple sclerosis. Med J Islam Repub Iran 2017; 31: 133.

8. Tarameshlu M, Ghelichi L, Azimi AR, Ansari NN, Khatoonabadi AR. The effect of traditional dysphagia therapy on the swallowing function in patients with Multiple Sclerosis: a pilot double-blinded randomized controlled trial. J Bodyw Mov Ther 2019; 23: 171-176.

9. Grandidge L, Chotiyarnwong C, White S, Denning J, Nair KPS. Survival following the placement of gastrostomy tube in patients with multiple sclerosis. Mult Scler J Exp Transl Clin 2020; 6: 2055217319900907.

10. Alali D, Ballard K, Vucic S, Bogaardt H. Dysphagia in multiple sclerosis: evaluation and validation of the DYMUS questionnaire. Dysphagia 2018; 33: 273-281.

11. Belafsky PC, Mouadeb DA, Rees CJ, Pryor JC, Postma GN, Allen J, et al. Validity and reliability of the eating assessment tool (EAT-10). Ann Otol Rhinol Laryngol 2008; 117: 919-924.

12. Patel DA, Sharda R, Hovis KL, Nichols EE, Sathe N, Penson DF, et al. Patient-reported outcome measures in dysphagia: a systematic review of instrument development and validation. Dis Esophagus 2017; 30: 1-23.

13. Golden LC, Voskuhl R. The importance of studying sex differences in disease: the example of multiple sclerosis. $J$ Neurosci Res 2017; 95: 633-643.

14. Milewska M, Grabarczyk K, Dąbrowska-Bender M, Jamróz B, Dziewulska D, Staniszewska A, et al. The prevalence and types of oral- and pharyngeal-stage dysphagia in patients with demyelinating diseases based on subjective assessment by the study subjects. Mult Scler Relat Disord 2020; 37: 101484.
15. Moccia M, Annovazzi P, Buscarinu MC, Calabrese M, Cavalla P, Cordioli C, et al. Harmonization of real-world studies in multiple sclerosis: retrospective analysis from the rirems group. Mult Scler Relat Disord 2020; 45: 102394.

16. Grasso MG, Gamberini G, Patti F, D'Amico E, Bergamaschi R, Berra E, et al. The dysphagia in multiple sclerosis questionnaire correlates with fiber-optic endoscopic examination for detecting swallowing deficits in MS. Dysphagia 2021; 36: 192-197.

17. Radulovic L, Erakovic J, Roganovic M. Attitudes of patients with relapsing-remitting form of multiple sclerosis using disease-modifying drugs in Montenegro regarding COVID-19 pandemic. Mult Scler Relat Disord 2020; 45: 102380.

18. Sales DS, Alvarenga RM, Vasconcelos CC, Silva RG, Thuler LC. Translation, cross-cultural adaptation and validation of the Portuguese version of the DYMUS questionnaire for the assessment of dysphagia in multiple sclerosis. Springerplus 2013; 2: 332.

19. Printza A, Triaridis S, Kalaitzi M, Nikolaidis I, Bakirtzis C, Constantinidis J, et al. Dysphagia prevalence, attitudes, and related quality of life in patients with multiple sclerosis. Dysphagia 2020; 35: 677-684.

20. Tenekeci EG, Kara B, Çetiz A, Demirkaya Ş, Demir N, Açikel C. Validity and reliability of the Turkish version of the questionnaire for the assessment of dysphagia in multiple sclerosis. Noro Psikiyatr Ars 2016; 55: 243-247.

21. Warnecke T, Dziewas R, Wirth R, Bauer JM, Prell T. Dysphagia from a neurogeriatric point of view : pathogenesis, diagnosis and management. Z Gerontol Geriatr 2019; 52: 330-335.

\section{Ethical Consent}

All manuscripts reporting the results of experimental investigations involving human subjects should include a statement confirming that informed consent was obtained from each subject or subject's guardian, after receiving approval of the experimental protocol by a local human ethics committee, or institutional review board. When reporting experiments on animals, authors should indicate whether the institutional and national guide for the care and use of laboratory animals was followed. 